\section{Comment on the 2019 update of the EULAR recommendations for the management of systemic lupus erythematosus by Fanouriakis et al}

We read with great interest the 2019 update of the European League Against Rheumatism (EULAR) recommendations for the management of systemic lupus erythematosus (SLE) by Fanouriakis et al. ${ }^{1}$ We believe that these recommendations may help to improve the management of SLE patients and the authors should be congratulated for their efforts. We disagree, however, on an important point. The authors state in the abstract and the recommendations that hydroxychloroquine (HCQ) is recommended for all patients with SLE (1b/A), unless contraindicated, at a dose not exceeding $5 \mathrm{mg} / \mathrm{kg} / \mathrm{real}$ body weight $(3 \mathrm{~b} / \mathrm{C})$. We fully agree with the first part of the sentence, since HCQ prevents flares, is much cheaper than other drugs widely used for SLE, protects against the occurrence of thrombotic events, diabetes, dyslipidaemia and overall damage accrual, and also appears to prolong survival. In contrast, we believe that the second part of the sentence, recommending less than $5 \mathrm{mg} / \mathrm{kg}$ is misleading for clinicians. We believe that two conditions should be present before recommending such a reduction of the prescribed dose of HCQ. First, this lower dose should have equal efficacy, which is largely unknown. Second, this dose should have been demonstrated to be safer, which is also not the case. Importantly, this dose of $5 \mathrm{mg} / \mathrm{kg}$ is based on an ophthalmological study by Melles and Marmor $^{2}$ of nearly 2500 patients, mostly with rheumatoid arthritis and older than 50 years, who were known from pharmacy records to have used HCQ continuously for more than 5 years. The overall prevalence of toxicity, defined with visual fields and modern imaging technique was $7.5 \%$, suggesting that with new ophthalmologic tests, HCQ toxicity may not be so rare among long-term HCQ users. ${ }^{2}$ The authors also found that daily HCQ intake below $5 \mathrm{mg} / \mathrm{kg}$ of regular body weight was associated with a low risk of toxicity, $<2 \%$ within the first 10 years of use. ${ }^{2}$ Since their study was based on pharmacy refill information, their estimates represent actual HCQ intake rather than prescribed dose. The authors estimated that in their population, this cut-off of $5 \mathrm{mg} / \mathrm{kg}$ corresponded to a prescribed dose of approximately $6 \mathrm{mg} / \mathrm{kg}$ real weight. ${ }^{2}$ In other words, although most of the patients were prescribed a daily dose of $6 \mathrm{mg} / \mathrm{kg}$, they were actually consuming close to $5 \mathrm{mg} / \mathrm{kg}$. In other populations, the disparity between the prescribed and actual drug dosage is known to be much larger, especially in young SLE patients. ${ }^{3} 4$ For instance, among 10406 Medicaid SLE patients who started on treatment with HCQ, the overall mean \pm SD proportion of day covered (which represented the proportion of days a patient had HCQ available during 1 year) was only $42 \% \pm 29 \%$. The implication is that, in this population, the cut-off of $5 \mathrm{mg} / \mathrm{kg}$ actually collected would correspond to a prescribed dose of 11.1 $\mathrm{mg} / \mathrm{kg}$. ${ }^{4}$ Since it is well known that adherence declines further over the years, this gap between the prescribed and actual intake dose may increase during the follow-up. Accordingly, the revised recommendations on screening for HCQ retinopathy published in 2016 clearly state that because of varying adherence and body habitus, $5 \mathrm{mg}$ of $\mathrm{HCQ} / \mathrm{kg}$ used corresponds with present medical prescription practices. ${ }^{5}$ It is, thus, difficult to recommend a maximum dose of $5 \mathrm{mg} / \mathrm{kg}$ without specifying that it refers to the true intake and that in reality, it means that we need to prescribe the same dose as the one we have been using for decades. Understanding this is important since some patients may require higher prescribed dose than $5 \mathrm{mg} / \mathrm{kg}$ to have therapeutic blood HCQ levels as well as clinical efficacy. ${ }^{36}$

Nathalie Costedoat-Chalumeau $\odot,{ }^{1}$ David Isenberg $\odot{ }^{2}$ Michelle Petri $\odot^{3}$

${ }^{1}$ Assistance Publique-Hôpitaux de Paris (AP-HP), Internal Medicine Department, Cochin Hospital, Referral center for rare autoimmune and systemic diseases, Paris, France; Paris Descartes Sorbonne, Paris Cité University, Paris, France; INSERM U

1153, Center for Epidemiology and Statistics Sorbonne Paris Cité, Paris, France

${ }^{2}$ Centre for Rheumatology, University College London, London, UK

${ }^{3}$ Rheumatology, Johns Hopkins University, Baltimore, Maryland, USA

Correspondence to Professor Nathalie Costedoat-Chalumeau, CCH Tagetik France, Paris 75014, France; nathalie.costedoat@gmail.com

Handling editor Josef S Smolen

Contributors All the authors wrote the letter.

Competing interests None declared.

Patient consent for publication Not required.

Provenance and peer review Not commissioned; internally peer reviewed.

(c) Author(s) (or their employer(s)) 2020. No commercial re-use. See rights and permissions. Published by BMJ.

Check for updates

To cite Costedoat-Chalumeau N, Isenberg D, Petri M. Ann Rheum Dis 2020;79:e90.

Received 18 April 2019

Accepted 25 April 2019

Published Online First 2 May 2019

\section{(5) Linked}

- https://doi.org/10.1136/annrheumdis-2019-215615

Ann Rheum Dis 2020;79:e90. doi:10.1136/annrheumdis-2019-215573

\section{ORCID iDs}

Nathalie Costedoat-Chalumeau http://orcid.org/0000-0002-1555-9021

David Isenberg http://orcid.org/0000-0001-9514-2455

Michelle Petri http://orcid.org/0000-0003-1441-5373

\section{REFERENCES}

1 Fanouriakis A, Kostopoulou M, Alunno A, et al. 2019 update of the EULAR recommendations for the management of systemic lupus erythematosus. Ann Rheum Dis 2019;78:736-45.

2 Melles RB, Marmor MF. The risk of toxic retinopathy in patients on long-term hydroxychloroquine therapy. JAMA Ophthalmol 2014;132:1453-60.

3 Costedoat-Chalumeau N, Pouchot J, Guettrot-Imbert G, et al. Adherence to treatment in systemic lupus erythematosus patients. Best Pract Res Clin Rheumatol 2013:27:329-40.

4 Feldman $\mathrm{CH}$, Collins J, Zhang Z, et al. Dynamic patterns and predictors of hydroxychloroquine nonadherence among Medicaid beneficiaries with systemic lupus erythematosus. Semin Arthritis Rheum 2018;48:205-13.

5 Marmor MF, Kellner U, Lai TYY, et al. Recommendations on screening for chloroquine and hydroxychloroquine retinopathy (2016 revision). Ophthalmology 2016;123:1386-94.

6 Durcan L, Clarke WA, Magder LS, et al. Hydroxychloroquine blood levels in systemic lupus erythematosus: Clarifying dosing controversies and improving adherence. J Rheumatol 2015:42:2092-7. 